\title{
A PRODUÇÃO DO CONHECIMENTO NA ÁREA DO LAZER: UMAA ANÁLISE SOBRE A REVISTA LICERE- ATUAÇÃO PROFISSIONAL ${ }^{1}$
}

\author{
Edmur Antonio Stoppa \\ Universidade de São Paulo, São Paulo, São Paulo, Brasil
}

Monica Delgado

Universidade Estadual de Campinas, Campinas, São Paulo, Brasil

André Chabaribery Capi

Universidade Federal de Minas Gerais, Belo Horizonte, Minas Gerais, Brasil

Nelson Carvalho Marcellino

Universidade Metodista de Piracicaba, Campinas, São Paulo, Brasil

\section{Resumo}

O trabalho tem como objetivo desenvolver estudos exploratórios nos exemplares da Revista Licere (única especializada na área de estudos do lazer, do país), sobre a temática: lazer e atuação profissional. Os dados coletados permitem afirmar que a Revista, a partir de sua política editorial, tem grande relevância na área do lazer, registrando, disseminando, além de colaborar na qualificação da produção na área da atuação profissional, elemento em constante processo de reflexão e mudança, pelas demandas e necessidades colocadas por ela, contribuindo assim, com o avanço qualitativo dos estudos e experiências desenvolvidas na área do lazer.

Palavras-chave: Artigo de revista. Atividades de lazer. Prática profissional.

\section{Introdução}

$\mathrm{O}$ s estudos do lazer no Brasil vêm crescendo significativamente. A partir de 1998, houve o surgimento de um periódico científico específico sobre lazer em nosso país - LICERE, Revista do Programa Interdisciplinar de Mestrado em Lazer, da Universidade Federal de Minas Gerais (UFMG).

A revista, que possui o apoio institucional do Centro de Estudos de Lazer e Recreação - CELAR - da Escola de Educação Física, Fisioterapia e Terapia Ocupacional da UFMG e do grupo de pesquisa ANIMA - Lazer, Animação Cultural e Estudos Culturais, têm como objetivos: "a) registrar, difundir e compartilhar publicamente o co-

1-O presente trabalho não contou com apoio financeiro de nenhuma natureza para sua realização. 
nhecimento construído na área do Lazer; b) contribuir com o avanço qualitativo dos estudos e experiências desenvolvidas" (LICERE, 2009, s.p.).

Desde 1998, a revista já publicou vinte e dois exemplares, sendo que, a partir de 2007, as publicações passaram a ser eletrônicas. Até o ano de 2008 era publicada quadrimestralmente. No entanto, no ano de 2009, a Licere passou a ser trimestral (março, junho, setembro e dezembro).

A revista é indexada pelo Sistema Regional de Información en Línea para Revistas Científicas de América Latina, el Caribe, España y Portugal, pela Literatura Latino-Americana e do Caribe em Ciências da Saúde, pelo Sistema Brasileiro de Documentação e Informação Desportiva e pelo Sport Research Intelligence Sportive.

Diante do exposto, fica claro que a revista Licere apresenta uma trajetória importante e desempenha papel significativo na produção científica nacional acerca dos estudos do lazer. Torna-se, assim, relevante uma análise crítica de suas publicações.

\section{Problema e objetivo}

Assim, o problema que a presente pesquisa levanta é identificar como têm sido desenvolvidas as pesquisas que tem a temática da atuação profissional na área do lazer e publicadas no único periódico científico específico sobre lazer em nosso país. O objetivo deste trabalho é desenvolver estudo exploratório nos exemplares da revista Licere sobre a temática lazer e atuação profissional, focalizando os aspectos: tipo de trabalho, termos utilizados (palavras-chave), referencial teórico utilizado (autores/as), metodologias utilizadas, públicoalvo e resultados da pesquisa; além de divulgar os resultados da pesquisa pelos meios mais variados, permitindo a circulação do conhecimento.

\section{Metodologia}

O estudo foi realizado mediante a combinação de pesquisas bibliográfica e empírica. Em relação ao método, enquanto trajetória de raciocínio trabalha-se com o materialismo histórico-dialético, na concepção de Antonio Gramsci (1979, 1981), em especial nos conceitos de hegemonia e contra-hegemonia e de intelectuais. Assim, o lazer 
é entendido como espaço de resistência, de possibilidade de formação de novos valores, questionadores da sociedade. Sua vivência e importância nos dias atuais são enfatizadas a partir do plano cultural (superestrutura), como um dos instrumentos de mudanças, apesar das limitações estruturais (infraestrutura) encontradas em nossa realidade. Portanto a abordagem será a histórica.

Quanto ao método, entendido como "procedimentos mais amplos de raciocínio" (SEVERINO, 2000, p. 162), ou como modo de observação, que constituem os meios de abordar o "real" (BRUYNE; HERMAN; SCHOUTHEETE, 1991), utilizou-se, para análise dos trabalhos publicados na Revista Licere, o estudo de caso.

Em relação às técnicas, utilizou-se para a pesquisa bibliográfica o levantamento inicial das obras relativas aos termos-chave, no Sistema de Bibliotecas da UNIMEP, USP, UFMG e UNICAMP, escolhidas por critérios, levados em conta conjuntamente, de representatividade (cursos na área dos estudos do lazer em funcionamento) e acessibilidade, além de ferramentas disponíveis na Rede Mundial de computadores.

Após essa etapa, as obras foram selecionadas e investigadas pelas análises textual, temática, interpretativa e de problematização (SEVERINO, 2000). No decorrer da pesquisa, foram incorporadas obras mais recentes sobre o tema em questão, ou que foram necessárias para o desenvolvimento da pesquisa bibliográfica.

Finalizada a pesquisa bibliográfica, a segunda etapa constituiu-se de um estudo exploratório (TRIVIÑOS, 2008) nos diversos exemplares da revista Licere, publicados desde 1998 até os dias atuais, analisados a partir dos aspectos enfocados nos objetivos específicos.

A Revista Licere apresenta, em cada um de seus exemplares, as seguintes seções fixas nas edições atuais: Artigos Originais, Artigos de Revisão, Relatos de Experiência, Tome Ciência e Fique por Dentro. Tendo em vista a necessidade de ter em mãos para análise textos mais completos e detalhados optou-se por analisar as seções Artigos, Artigos Originais e Relatos de Experiência, que com essa temática, passaram a ser publicados nas edições a partir do volume 12, de março de 2009. Complementando a análise foram pesquisadas outras seções nos exemplares anteriores publicados entre março de 1998 e de 2009, abordando o assunto, tais como Múltiplos Olhares, Vivências Cotidianas e Espaço do CELAR. 
Para a etapa quantitativa foi utilizada uma ficha para a coleta de dados gerais sobre as produções dos diversos artigos. Nesse sentido foram analisados os artigos na revista em relação ao tipo de seção na revista, palavras-chaves, referencial teórico utilizado, instituição de origem do pesquisador, natureza da instituição - foco da pesquisa, titulação dos autores e área de atuação do(s) autor(es).

Para a análise qualitativa dos textos selecionados, tendo como referência a análise textual, interpretativa e crítica, sugerida por Severino (2000), foi utilizada uma segunda ficha de coleta de dados, com novos campos definidos de acordo com cada linha de pesquisa, a partir de suas especificidades temáticas, para maior aprofundamento das questões a serem analisadas. Essa etapa do trabalho focalizou elementos como tipo de trabalho, palavras-chaves, referencial teórico utilizado nos trabalhos, metodologias utilizadas, público-alvo e resultados da pesquisa.

A definição das amostras deu-se de forma não probabilística, intencional, para os exemplares da Revista Licere a ser estudada, levando em conta critérios de representatividade e acessibilidade (BRUYNE; HERMAN; SCHOUTHEETE, 1991).

\section{A atuação profissional na realidade brasileira}

O lazer vem sendo caracterizado como um espaço de atuação interdisciplinar, possibilitando a participação de profissionais de diversas áreas (educação física, educação, turismo, arte-educação, psicólogos, arquitetos, entre outros).

Atualmente, com o crescimento do setor de prestação de serviços na área de lazer, o número de ofertas de emprego para os profissionais que desejam atuar nesta área vem aumentando consideravelmente.

Tal questão leva-nos a observar o aparecimento de uma grande diversidade de funções que estes profissionais podem assumir, tais como: o planejamento, a organização, a administração, a animação e a avaliação de atividades de lazer. Desta forma, podemos encontrar profissionais trabalhando com formação diferenciada em várias instituições públicas (prefeituras, universidades, secretarias) e privadas (hotéis, clubes, acampamentos, academias de ginástica, empresas de viagens, entre outras), bem como organizações ligadas ao terceiro setor. 
Complexa e diversificada é a caracterização do profissional que trabalha com o lazer. Encontramos as mais diferentes denominações, tais como: monitor de lazer, recreacionista, militante cultural, consultor de lazer, animador cultural, entre outras. No entanto, optamos pelo termo "animador cultural", que é proposto por alguns autores (SILVESTRE NETO, 1980; MARCELLINO, 1986; PINA, 1995). Essa terminologia se deve ao fato de que a atuação deste profissional deva ocorrer num contexto mais amplo, buscando uma transformação da sociedade, possibilitada por meio da participação cultural crítica e criativa.

A animação cultural caracteriza-se como uma atividade desenvolvida por profissionais ou amadores que possuam interesse em pelo menos um setor cultural (artístico, fisico-desportivo, intelectual, entre outros) e que possuam como característica básica à vontade de difundir esse bem cultural (MARCELLINO, 1986). A ação dos animadores deve, então, estar baseada na competência técnica, na democratização cultural, na participação coletiva e no compromisso com a mudança na ordem social estabelecida.

Porém, mesmo concordando com as questões acima é importante estarmos atentos com os possíveis riscos que possam surgir a partir da atuação dos profissionais, uma vez que, ao invés de privilegiar a participação, podem incentivar o contrário, a não participação.

Discutindo esses possíveis riscos, Marcellino (2000) enumera alguns, tais como: possibilidade de direcionamento das atividades, deixando de lado o papel pedagógico da animação, contribuindo para reforçar os valores da ideologia dominante ou encorajando práticas tradicionais; a realização dos "pacotes" de lazer, elaborados nos gabinetes, para simples consumo; tendência ao isolamento profissional restrito a um único conteúdo cultural; a visão "moralista" do lazer podendo transformá-lo numa espécie de censor das manifestações; tendência à valorização das suas preferências em termos de conteúdo e gêneros; e riscos devido à atuação institucionalizada.

No nosso entender, a atuação do profissional, que chamamos de animador cultural, se faz necessária por dois motivos principais: primeiro, por adotarmos uma concepção de lazer que considera o papel de desenvolvimento pessoal e social como um dos pilares básicos do lazer. O segundo ponto está relacionado ao conjunto de barreiras presentes na prática do lazer, que tem como pano de fundo o fator econômico, alicerçado nos preconceitos disseminados contra grande parte 
da população (mulheres, crianças, idosos, pessoas com deficiência, entre outros).

Outra questão importante em relação à atuação profissional na área do lazer é a necessidade da ação profissional estar ligada diretamente aos interesses da população a ser atingida, o que requer da ação profissional uma atuação conjunta entre as diferentes funções ligadas ao lazer.

Atento a essas questões Pina (1995) discute a necessidade de a atuação profissional estar calcada em uma estrutura de animação sociocultural de formas piramidal, divida em cargos e funções de acordo a figura I abaixo.

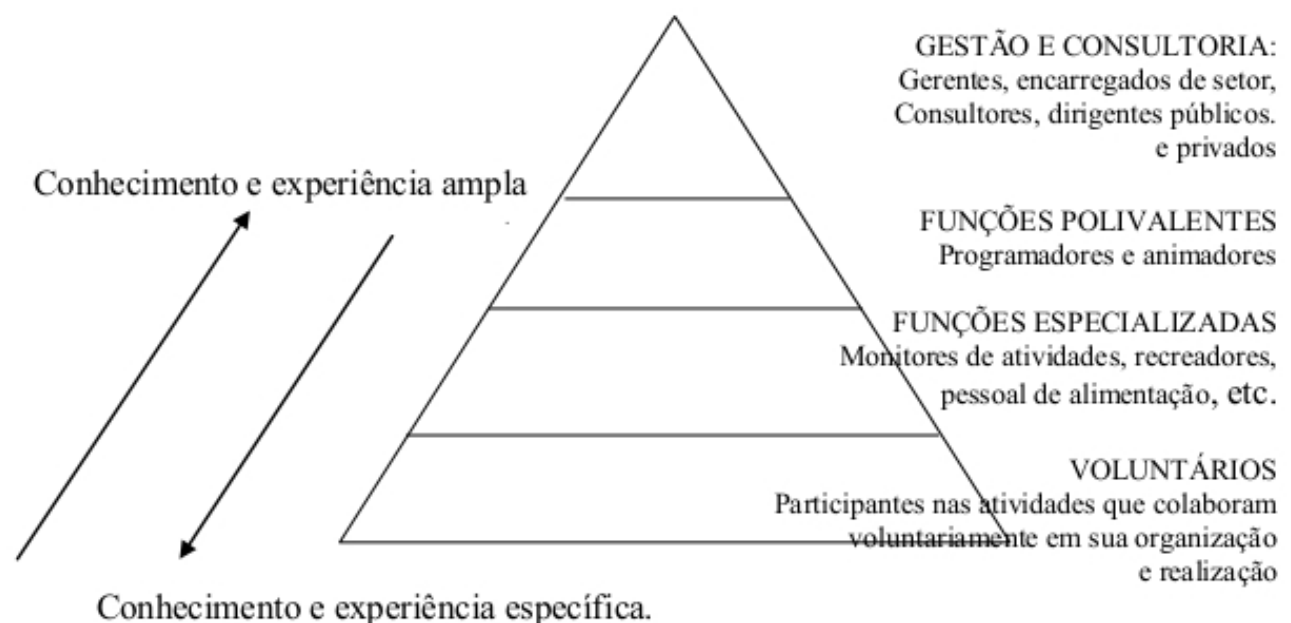

Figura I: PINA (1995, p. 126)

Essa estrutura de animação sociocultural tem se mostrado bastante interessante na sua aplicação nos espaços de lazer. A estrutura de animação é dividida em quatros categorias, tendo cada uma delas características diferentes, de acordo com a função a ser desempenhada pelo profissional. Quanto mais próximo do vértice da pirâmide, mais amplo e diversificado deve ser o conhecimento e experiência, pois a atuação será desenvolvida em cargos de administração, coordenação, consultoria, etc. Quanto mais próximo da base, mais específico deve ser o conhecimento e a experiência, a fim de atuar com a monitoria das diferentes atividades de lazer.

E aqui cabe destaque ao papel do voluntariado nas ações, junto à atuação dos profissionais de lazer. Representantes das diferentes comunidades com as quais os especialistas de lazer podem trabalhar, os voluntários são elementos facilitadores das ações, funcionando como 
ponto de ligação entre os especialistas e a comunidade como um todo. As ações dos voluntários podem ser entendidas como uma possibilidade de minimizar os riscos advindos da ação do "especialista" tradicional, uma vez que todo planejamento ${ }^{2}$ parte das necessidades, desejos e expectativas, a partir da análise de situação em que se encontra a comunidade.

Uma estrutura de animação capacitada, atuante e participativa é papel central para que o lazer possa ser vivenciado como instrumento de mudança e gerador de novos valores em nossa sociedade.

Se a participação profissional é de suma importância para que esse processo se estabeleça, mais importante ainda é a presença dos voluntários como forma de multiplicação das ações. Longe de ser entendido como alternativa para mão-de-obra barata, ou ainda, como concorrentes aos profissionais, o voluntariado é a ligação entres esses profissionais e a comunidade mais ampla.

Para Paiva (2003), a ação profissional, a partir do voluntariado, tem maiores chances de ser bem sucedida se esta estiver ligada à cultura das comunidades. Para ele, a relação entre a proposta técnica e a realidade local é de extrema importância para definição das ações. Além disso, é necessário que haja a efetiva participação dos voluntários no planejamento, na execução e na avaliação dos programas e das políticas, de modo a capacitar o conhecimento técnico e político do grupo.

Mais do que mão de obra barata, portanto, busca-se com esse tipo de ação a capacitação e multiplicação das comunidades para, que juntos com os profissionais de competência geral e específica, o estabelecimento de políticas de lazer compromissadas com o desenvolvimento da cidadania, da democratização cultural.

\section{Resultados e discussão}

Podemos destacar como principais dados da pesquisa quantitativa as seguintes questões:

Foram selecionados trinta e quatro trabalhos.

Em relação ao tipo de trabalho apresentado nas diferentes seções

2-Sobre a ação dos voluntários como possibilidade de minimização dos riscos na ação dos "especialistas" tradicionais ver Marcellino (1996a) ou, ainda, Paiva (2003). 
da revista, 35,2\% foram Artigos, 50\% Artigos Originais, 8,9\% foram na seção Múltiplos Olhares e 5,9\% Espaço do CELAR.

Quanto às palavras chaves e a frequência nos trabalhos, das sessenta e oito diferentes palavras encontradas, "Lazer" foi a que teve a maior presença com dezessete citações, seguido de "Animação Cultural" com seis frequências e "Cultura" e "Educação Física" com três frequências. Foram também identificados seis trabalhos sem a colocação de palavras-chaves.

No que diz respeito ao referencial teórico utilizado foram levantados noventa e quatro diferentes referências e destes os mais citados no total foram Marcellino com quarenta e nove citações, Camargo e Cevasco com catorze, Munné com doze e Mello com onze citações.

Quanto à instituição de origem do pesquisador $55,4 \%$ são de instituições públicas, $43,1 \%$ de instituições privadas e 1,5\% não apontam a origem da instituição. Das instituições públicas, $72,2 \%$ são federais, $25 \%$ são estaduais e 2,8 são municipais. Em relação ao foco da pesquisa, das 39 instituições levantadas, $17,7 \%$ são relacionadas ao setor Corporativo, $47 \%$ ao Público Não-Governamental, $40 \%$ ao Publico Governamental, $20,6 \%$ ao Privado e $14,7 \%$ outros.

Destaca-se nessa questão a participação das Universidades na produção do conhecimento, principalmente a privada, uma vez que pesquisa semelhante publicada pelo GPL (STOPPA et al., 2010) apontava uma supremacia da universidade pública em relação à privada na produção do conhecimento e publicação nos anais do ENAREL. Naquela ocasião já chamávamos a atenção para o fato de tal situação poder ser justificada pelo papel social destinado à universidade. A pesquisa apontava que as instituições com essa características deviam desenvolver suas ações a partir do tripé ensino - pesquisa - extensão, articulando o conhecimento produzido pela academia com a realidade social onde esta está inserida, ao contrário das demais instituições, onde o ensino tem maior destaque, seja pelo papel social delegado a estas, seja pelo pouco apoio que os professores e alunos possuem na realização de pesquisas.

Dos 63 autores presentes nos trabalhos, $28,6 \%$ são doutores, $20,7 \%$ são mestres, $6,3 \%$ são especialistas, $11,1 \%$ são graduados, $6,3 \%$ são estudantes e $27 \%$ são outros. Destes $23,5 \%$ são livre-docentes e $76,5 \%$ não apresentam informação. Em relação à área de atuação destes autores $26,4 \%$ atuam com a pesquisa, $2,3 \%$ com a gestão, $42,5 \%$ com a docência e $28,8 \%$ com outras áreas de atuação. 
Em relação aos dados qualitativos os principais resultados que podem ser apontados são:

A atual pesquisa teve início com uma análise quantitativa seguida de uma análise qualitativa dos artigos publicados na revista Licere. Para Schwartz et al. (2006, p.87) "[...] as estratégias utilizadas para o desenvolvimento de pesquisas com o design qualitativo procuram promover a visão existencial do homem, aprofundando-se na compreensão dos fenômenos sociais, tanto de forma inter, quanto multidisciplinar".

Assim, quanto à paginação dos artigos nas edições publicadas e analisadas na pesquisa em questão, os dados apontam que a partir do momento que a revista deixa de ser editada em papel, ou seja, a partir do volume 10 , número 1 , de abril de 2007, os artigos deixam de indicar os números das páginas. Dos trinta e quatro artigos levantados na segunda fase, dezessete não possuem a paginação em ordem serial como a encontrada na revista editada em papel.

Em relação ao tipo de material, os dados apontam que 14,8\% enquadram-se como "Ponto de Vista", 29,4\% como "Artigo de Revisão", $50 \%$ como "Artigo de Pesquisa" e 5,8\% como "Relato de Experiência". Destaque para a categoria "Artigo de Pesquisa" como metade da produção nas seções analisadas da revista. Tal dado tem relação direta com as produções realizadas em Universidades, seja em programas de Mestrado e Doutorado, seja nos grupos de pesquisa da área do lazer vinculados à temática da atuação profissional.

No que diz respeito à discussão principal do texto em relação à atuação profissional, 67,7\% são relacionadas à discussão conceitual, $23,5 \%$ são ligados a relatos de experiência, 5,9\% sobre formulação de políticas e $2,9 \%$ relacionadas às experiências de gestão em diferentes instituições que desenvolvem ações na área do lazer.

De forma contrária à categoria anterior chama à atenção a baixa porcentagem de trabalhos ligados à formulação de políticas de ação e de experiências de gestão, apesar do alto número de artigos conceituais e de relatos de experiência. A questão que pode ser colocada aqui é a seguinte: até que ponto a produção de conhecimento na área da atuação profissional no lazer tem revertido esse conhecimento na formulação de políticas para a área, bem como para a gestão do lazer, influenciado a ação profissional na área. A distância geralmente encontrada em relação ao conhecimento produzido na universidade e as 
diferentes áreas de intervenção da sociedade civil tem se mostrado de que forma na área do lazer?

Quanto à metodologia várias questões podem ser apontadas pelos dados coletados. Em relação ao tipo de pesquisa, dos trinta e quatro artigos que foram analisados, vinte deles não explicitam o tipo de pesquisa, sendo que em dezessete deles é possível detectar, através da leitura, em que categoria de pesquisa o texto se insere, somando-se, ao total, trinta e um artigos nos quais podemos perceber a categoria na qual a pesquisa se enquadra, sendo elas: vinte e oito pesquisas bibliográficas, sete pesquisas documentais e doze pesquisas empíricas. Em quatorze artigos existe uma combinação de mais de um tipo de pesquisa. Foram citadas também duas pesquisas exploratórias, duas de campo e uma de caráter descritivo.

Nesse item da análise, os tipos e quantidade de pesquisas apresentadas como artigo para a revista Licere são semelhantes àquelas que foram analisadas pelo GPL na pesquisa realizada sobre o ENAREL publicada na Licere (STOPPA, et al., 2010). Pela vivência nesse encontro e as leituras da revista Licere, percebemos que algumas pessoas que participam do evento são também autores de artigos na revista, ou fazem parte dos mesmos grupos de pesquisa e, por isso, os mesmos tipos de análises são realizados.

Na pesquisa mencionada acima já apontávamos que na medida em que a área busca sua consolidação e desenvolvimento conceitual, os estudos empíricos tem tido destaque, fato aqui também apontado pela grande quantidade de artigos de pesquisa, que de acordo com Demo (2000, p. 21) busca analisar a "face empírica da realidade" produzindo e analisando dados pela via do controle fatual. Para ele, a valorização desse tipo de pesquisa se dá pela

[...] possibilidade que oferece de maior concretude às argumentações, por mais tênue que possa ser a base fatual. $\mathrm{O}$ significado dos dados empíricos depende do referencial teórico, mas estes dados agregam impacto pertinente, sobretudo no sentido de facilitarem a aproximação prática (DEMO, 1994, p. 37).

Já os trabalhos de cunho bibliográfico buscam conhecer e analisar contribuições culturais do passado, para que com os conhecimentos ali adquiridos se possam obter dados para a atual pesquisa (CERVO; BERVIAN, 1978). 
Dos trinta e quatro trabalhos analisados, com relação ao método como trajetória de raciocínio, em vinte e nove artigos o método não está explícito. Pela leitura, em menos da metade desses artigos, ou seja, em catorze deles, é possível identificar a categoria no qual ele se insere. Assim como foi constatado na pesquisa realizada pelo GPL sobre o ENAREL (STOPPA, et al., 2010), com relação às abordagens histórico-críticas nos estudos do lazer, na pesquisa atual a influência do materialismo histórico-dialético também continua marcante. Dos dezenove trabalhos analisados onde é possível se verificar qual foi o método como trajetória de raciocínio utilizado, catorze seguem a linha do Materialismo Histórico-Dialético, três a linha Fenomenológica e apenas um a linha Hipotético-Dedutiva.

Esse número pode ser justificado uma vez que a grande maioria dos profissionais da área de Lazer tem a formação em Educação Física, e a mesma "avançou para entender seu papel conceitual, procedimental e atitudinal na formação desses profissionais, relacionando mais o lazer, trabalho e exigências da vida como um todo" (GOMES; PINTO, 2009, p.89) e sendo o materialismo histórico-dialético um método de interpretação da realidade, a mudança de paradigma que a Educação Física vem sofrendo nas últimas décadas pode estar priorizando esse tipo de abordagem.

Com relação ao item investigado "método como modo de investigação", dos trinta e quatro trabalhos, na sua grande maioria, em vinte e seis, o método utilizado não estava explícito. Com a leitura do artigo em dez deles pode ser detectado o método utilizado, somando-se, então, dezoito artigos onde o método pode ser apontado, sendo que destes, onze artigos se enquadram na categoria Estudo de Caso e seis em Estudos Comparativos. Em um artigo o autor não utiliza o método como modo de investigação dentro da sua abordagem conceitual. Nenhum artigo utilizou o método de Experimentação ou o de Quase experimentação.

Como no método experimental o pesquisador manipula e controla uma ou mais variáveis independentes, podemos então presumir que a inexistência de pesquisas que utilizam a experimentação ou a quase experimentação se deve ao fato das ciências sociais serem à base dessas pesquisas e o homem e sua relação com a sociedade, o objeto, o estudo das pesquisas, sendo uma variável de difícil controle.

O processo metodológico utilizado no desenvolvimento de qualquer trabalho acadêmico influencia nos seus resultados. A coleta de 
dados é uma categoria utilizada no desenvolvimento desses trabalhos e a sua aplicabilidade pode e deve ser utilizada por meio de várias técnicas com o intuito de reunir um feixe de dados ao mesmo tempo disponíveis, acessíveis e conformes a seu objeto de investigação (BRUYNE; HERMAN; SCHOUTHEETE, 1991).

Nessa pesquisa também analisamos as técnicas de obtenção de dados e de amostragem dos trinta e quatro trabalhos investigados. Catorze fichas explicitaram as técnicas de obtenção de dados por meio de entrevistas (quatro delas), questionários (três) e combinação de técnicas (seis), enquanto em vinte trabalhos essas técnicas não estavam explicitas no texto, mas, no entanto, no decorrer da leitura do artigo foi possível identificar tal categoria em quatro deles (dois utilizando observação participante e dois questionários).

As técnicas de amostragem estavam explicitas em sete trabalhos, sendo cinco de maneira não probabilística e dois num viés probabilístico. Dos outros vinte e sete trabalhos, em vinte e dois não foram identificados esta categoria e nos cinco em que isso foi possível observamos uma amostragem não probabilística.

Outro elemento observado na pesquisa foi a presença ou não do resumo do trabalho no artigo publicado. Constatamos que vinte e nove artigos apresentavam o resumo e somente cinco não o disponibilizava. Tal fato se dá devido a esses artigos terem sidos publicados nas seções "Múltiplos Olhares" e "Espaço do CELAR" em edições anteriores a março de 2009, espaços em que os autores foram convidados a escrever sobre assuntos de interesse da revista.

Os artigos que possuem resumos têm sua reflexão e discussão relacionada a diferentes aspectos da atuação profissional, em grande parte relacionada à discussão sobre a animação cultural ou sociocultural. São encontrados quatro textos ligados a clubes social-recreativos, um que analisa a relação do lazer com outras áreas de atividade humana e os conceitos de tempo disponível ou tempo livre, um relacionado a acampamentos de férias, dois relacionados à animação hoteleira, três que abordam a relação lazer, animação cultural e educação, quatro relacionados à animação cultural nos interesses artísticos do lazer, como o cinema e o teatro, um que analisa o perfil do profissional de lazer em Santa Catarina, um relacionado à discussão do lazer e cultura em lei de incentivo cultural, dois que abordam a relação lazer e saúde, dois relacionados à atuação profissional na Educação Física junto à infância, um sobre animação cultural e internet, 
seis vinculados à reflexão sobre a animação cultural e a educação em espaços públicos e um abordando a questão da atuação profissional no lazer e a produção do conhecimento na área.

\title{
Considerações finais
}

Com base nos dados coletados e analisados no decorrer do trabalho é possível apontar que a área do lazer tem apresentado importantes trabalhos e pesquisas relacionadas à temática da atuação profissional, apresentando e refletindo diversas experiências em diferentes espaços de atuação, quer seja no setor público governamental e não governamental, privado, ou terceiro setor.

Tal questão é importante à medida que as pesquisas publicadas na revista Licere podem subsidiar e respaldar novas formas de atuação profissional, além de incentivar a realização de novos trabalhos relativos à temática.

A ação do profissional como importante elemento para a vivência do lazer enquanto possibilidade de participação cultural e efetivo desenvolvimento da cidadania é fator a ser levado em consideração nas ações ligadas às diferentes políticas de lazer.

Assim, a Revista LICERE, Revista do Programa Interdisciplinar de Mestrado em Lazer, da Universidade Federal de Minas Gerais tem grande relevância na área do lazer, registrando, disseminando, além de colaborar na qualificação da produção na área da atuação profissional, a partir de sua política editorial, elemento em constante processo de reflexão e mudança, a partir das demandas e necessidades colocadas pela área do lazer, de forma a contribuir com o avanço qualitativo dos estudos e experiências desenvolvidas na área do lazer.

Knowledge production in the field of leisure: an analysis of Licere Magazine professional practice

\begin{abstract}
The aim of the present paper is to develop exploratory studies on leisure and professional performance in copies of Licere Magazine (the only journal in the country specialized in the field of leisure studies). The collected data allow us to state that, due to its editorial policy, the Magazine is highly significant in the field of leisure, recording, disseminating, and collaborating in the qualification of productions in the area of professional performance, an element in a constant process of reflection and change due to its demands and needs, thus contributing to the quali-
\end{abstract}


tative advance in the studies and experiences developed in the field of leisure.

Keywords: Journal article. Leisure activities. Professional practice.

La producción del conocimiento en el área del ocio: un análisis sobre el Magazine Licere - prácticas profesional

\section{Resumen}

El artículo tiene como propósito desarrollar estudios exploratorios en los ejemplares del Magazine Licere (único especializado en el área de estudios del ocio en Brasil) sobre el siguiente tema: ocio y actuación profesional. Los datos recogidos permiten afirmarse que el Magazine, desde su política editorial, tiene grande relevancia en el área del ocio, registrando, diseminando, allá de colaborar en la cualificación de la producción en el área de la actuación profesional, elemento en constante proceso de reflexión y cambio, por las demandas y necesidades colocadas por ella, contribuyendo así con el avanzo cualitativo de los estudios y experimentos desarrollados en el área del ocio.

Palabras clave: Artículo de revista. Actividades recreativas. Práctica profesional.

\section{Referências}

BRUYNE, P. de; HERMAN, J.; SCHOUTHEETE, M. de. Dinâmica da pesquisa em ciências sociais. 5. ed. Rio de Janeiro: Francisco Alves, 1991.

CERVO, A. L.; BERVIAN, P. A. Metodologia Científica. 2. ed. São Paulo: McGraw-Hill do Brasil, 1978.

DEMO, P. Saber Pensar. São Paulo: Cortez, 2000.

. Pesquisa e construção do conhecimento: metodologia científica no caminho de Habermas. Rio de Janeiro: Tempo Brasileiro, 1994.

GOMES, C. L.; PINTO, L. M. S. M.. Brasil: O lazer analisando práticas culturais cotidianas, acadêmicas e políticas. In GOMES, C. L.; OSORIO, E.; PINTO, L. M. S. M.; ELIZALDE, R. (Orgs.). Lazer na América Latina/Tiempo libre, ocio y recreación en Latinoamérica. Belo Horizonte: UFMG, 2009. p. 67-180

GRAMSCI, A. Os intelectuais e a organização da cultura. Rio de Janeiro: Civilização Brasileira, 1979. 
GRAMSCI, A. Concepção dialética da História. 4. ed. Rio de Janeiro: Civilização Brasileira, 1981.

MARCELlinO, N. C. Estudos do lazer: uma introdução. 2. ed. Campinas: Papirus, 2000.

. Lazer: animação e participação cultural. Comunicarte, Campinas, v.04, n. 08, p. 61-68, jul./dez., 1986

. Pressupostos da ação comunitária: estruturas e canais de participação. In: (Org.). Políticas públicas setoriais: o papel das prefeituras. Campinas: Autores Associados, 1996a. p. 39-42

. Subsídios para uma política de lazer: o papel da administração municipal. In: . (Org.). Políticas públicas setoriais: o papel das prefeituras. Campinas: Autores Associados, 1996b. p. 23-30.

PAIVA, J. L. Por um voluntário local. In: MARCELLINO, N. C. (Org.). Formação e desenvolvimento de pessoal em lazer e esporte: para atuação em políticas públicas. Campinas: Papirus, 2003 p. 157170.

PINA, L. W. Multiplicidade de profissionais e de funções. In: MARCELLINO, N. C. (Org.). Lazer: formação e atuação profissional. Campinas: Papirus, 1995. p. 117-130.

LICERE. Política Editorial. 2009. Disponível em: <http://www.anima.eefd.ufrj.br/licere/docs/politica.html>. Acesso em: 22 set. 2009.

SCHWARTZ, G. M. et al. A pesquisa qualitativa no âmbito dos estudos do lazer: análise das produções do ENAREL. Licere, Belo Horizonte, v. 9, n. 2, p.85-97, jul./dez., 2006.

SEVERINO, A. J. Metodologia do trabalho científico. 21. ed. São Paulo: Cortez, 2000.

SILVESTRE NETO, D. "Quem é o animador cultural?" Leituras Celazer. São Paulo: SESC, 1980. p. 1-4.

STOPPA, E. A. et al. A produção do conhecimento na área do lazer: uma análise sobre as temáticas formação e atuação profissional nos 
anais do ENAREL de 1997 a 2006. Licere, Belo Horizonte, v. 13, n. 2, p. 1-22, jun./ago., 2010.

TRIVIÑOS, A. N. S.. Introdução à pesquisa em ciências sociais: a pesquisa qualitativa em educação. São Paulo: Atlas, 2008.

Recebido em: 30/03/2012

Revisado em: 03/07/2012

Aprovado em: 30/07/2012

Endereço para correspondência

stoppa@usp.br

Edmur Antonio Stoppa

Universidade de São Paulo, USP Leste, Escola de Artes, Ciências e Humanidades

Av. Arlindo Bettio, 1000

Ermelino Matarazzo

03828-000 - Sao Paulo, SP - Brasil

Telefone: (11) 30918870 